\title{
Study on Characteristics of Air Pollution at Highway Toll Stations in Dalian, China
}

\author{
Yang Lv ${ }^{\text {a }}$, Zhimeng Wang, Tongke Zhao, Chenjia Wei, Xianzi Zhen, and Bin \\ Chen
}

\author{
School of Civil Engineering, Dalian University of Technology, China 116024
}

alvyang@dlut.edu.cn

\begin{abstract}
Keywords: Highway toll station; Air pollution; Traffic volume; External pollution
Abstract. People who work in highway toll station is suffering serve air pollution, due to where vehicles are crowded. So it is important to study the air pollution in highway toll stations. In this study, two toll stations in Dalian were chosen to measure the $\mathrm{CO}, \mathrm{PM}_{10}, \mathrm{NO}_{2}$ and total hydrocarbon (THC) inside and outside the toll stations. It was found that inside concentrations of $\mathrm{PM}_{10}$ exceed China Indoor Air Quality Standard (GB/T1883-2002) and outside concentrations of CO, $\mathrm{PM}_{10}$ and $\mathrm{NO}_{2}$ exceed China Environment Air Quality Standard (GB3095-2012). The factors affecting the air pollution at toll stations were the traffic volume, source of external pollution, including industrial soot pollution and coal-fire nearby, and diffusion.
\end{abstract}

\section{Introduction}

Traffic air pollution, as a high proportion of ambient pollution in megacities [1,2], is becoming the main source of air pollution in the city. The data of gas emission of UK in 2010 showed that $18 \%$ of inhalable particulates $\left(\mathrm{PM}_{10}\right), 24 \%$ of particulate matter $2.5\left(\mathrm{PM}_{2.5}\right), 54 \%$ of carbon monoxide $(\mathrm{CO})$, $32 \%$ of nitrogen oxide $\left(\mathrm{NO}_{\mathrm{x}}\right)$ and $26 \%$ of benzene were derived from traffic emission [3]. The United States Environmental Protection Agency (USEPA) on air quality reported that in 2010 the United States domestic traffic emissions of $\mathrm{PM}_{10}, \mathrm{PM}_{2.5}, \mathrm{CO}$ and $\mathrm{NO}_{\mathrm{x}}$ were in a larger proportion of the total emissions, especially CO accounted for around 60\% [4]. Mounting epidemiological studies found that long-term exposure to these pollutants increases the incidence and mortality of cardiovascular disease [5,6] and respiratory disease [7].

The traffic pollution in China is becoming more serious. $\mathrm{CO}$ accounted for $80 \%$ and $\mathrm{NO}_{\mathrm{x}}$ accounted for $40 \%$ to the ambient pollution in Beijing, Shanghai, Guangzhou and other large cities [8]. Meanwhile, the concentrations of $\mathrm{CO}$, sulfur dioxide $\left(\mathrm{SO}_{2}\right)$ and $\mathrm{NO}_{\mathrm{x}}$ in Chinese cities were 7 - 8 times, 8 - 10 times and 3 - 4 times than that in developed countries, respectively [9]. Evermore, the traffic emission of $\mathrm{PM}_{10}$ and $\mathrm{PM}_{2.5}$ accounted for $10 \%-15 \%$ and $20 \%-30 \%$ in ambient $\mathrm{PM}_{10}$ and $\mathrm{PM}_{2.5}$ [9]. It showed that highway traffic had greatly worsened the environmental air quality and long-term exposure to such an environment would have a great negative effect on the health of the human body.

Therefore, our study selected toll station of Zhoushuizi airport in Dalian and toll station of Dalian as the research objects, with monitoring the $\mathrm{CO}, \mathrm{PM}, \mathrm{NO}_{2}$ and total hydrocarbon (THC) inside and outside toll gates. The characteristics and influencing factors of air pollution in toll stations of North highway were studied.

\section{Methods}

Measurement Sites. In our study, two toll stations were chosen, one of which was Toll Station of Dalian (TSD) and the other one was a Toll Station of Zhoushuizi Airport (TSZA). TSD was far from the urban area, with spacious terrain and without obvious pollution source nearby. There were 22 toll gates with a daily traffic flow capacity of around 17000 vehicles. TSZA was closer to the urban area than TSD, which was within an industrial district. There were ten toll gates with a daily traffic flow capacity of around 8000 vehicles. Our measurement was carried out in December, 2012. During the measurement, the ambient temperature was $2-5^{\circ} \mathrm{C}$ and the northerly wind was $3 \mathrm{rd}-4$ th level. 
The measuring points in TSD and TSZA were shown in Fig. 1. The points 1, 2, 3 and 4 were inside the toll gate and point 5, 6, 7 and 8 were outside the toll gate. We chose a gate in each toll station. There were totally eight measuring points located at inside and outside a toll gate to test. Points 2 and 6 were close to the window. In addition, another measuring point was located at open space which was far from the toll gate rather than the road. Measuring time was between 9 a.m. to 6 p.m..

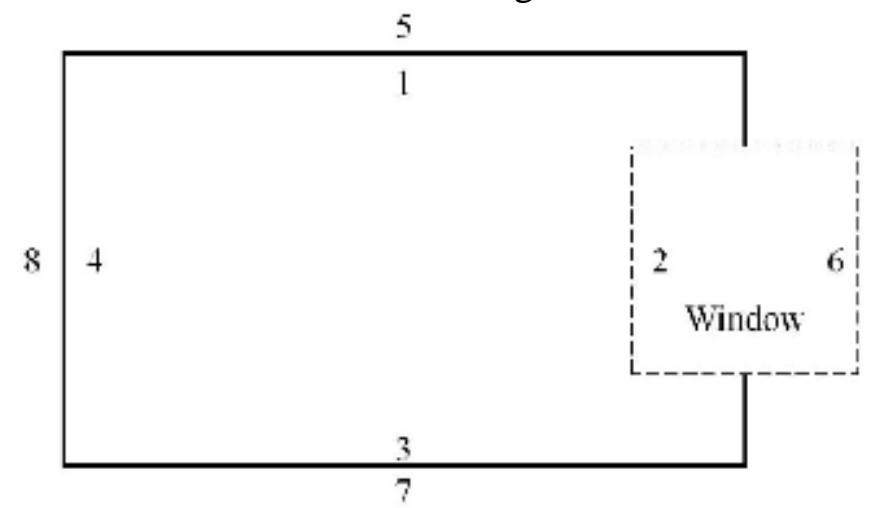

Fig. 1. The schematic diagram of a toll station and measuring points inside and outside.

Air Pollution Measurement. Our study measured carbon monoxide (CO), particulate matter $\left(\mathrm{PM}_{10}\right)$, nitrogen dioxide $\left(\mathrm{NO}_{2}\right)$ and total hydrocarbons (THC). The $\mathrm{CO}$ was measured by an indoor air quality tester (TSI 7545, Shoreview, MN, USA); the $\mathrm{PM}_{10}$ was measured by a DustTrak (TSI 8520, Shoreview, MN, USA); the $\mathrm{NO}_{2}$ was measured by a gas detector (G80-NO $\mathrm{N}_{2}$, OEM Collecting Inc. Co., Shenzhen, China); and the THC was measured by a detector (SNC2000-NMHC, Fuzhan, Shanghai, China). The measurement rate were all set as one per minute.

\section{Results and Discussion}

The Concentrations of pollutants inside and outside the Toll gates. This study measured air quality parameters inside and outside of toll gates in TSD and TSZA. All concentrations of pollutants of these points were showed in Table 1 . The mean concentrations of pollutants inside the toll gate were $8.56 \mathrm{mg} / \mathrm{m}^{3}$ of $\mathrm{CO}, 0.19 \mathrm{mg} / \mathrm{m}^{3}$ of $\mathrm{PM}_{10}, 0.21 \mathrm{mg} / \mathrm{m}^{3}$ of $\mathrm{NO}_{2}$ and $6.61 \mathrm{mg} / \mathrm{m}^{3}$ of THC, respectively. The mean concentrations of pollutants outside the toll gate were $10.68 \mathrm{mg} / \mathrm{m}^{3}$ of CO, $0.21 \mathrm{mg} / \mathrm{m}^{3}$ of $\mathrm{PM}_{10}, 0.25 \mathrm{mg} / \mathrm{m}^{3}$ of $\mathrm{NO}_{2}$ and $7.06 \mathrm{mg} / \mathrm{m}^{3}$ of $\mathrm{THC}$, respectively. All mean concentrations of pollutants inside were less than that outside. So the major source of pollution was come from outside due to vehicles were crowded with idling and acceleration which would cause much pollutants emission [10].

Table 1. The concentrations of pollutants of toll station inside and outside $\left[\mathrm{mg} / \mathrm{m}^{3}\right]$

\begin{tabular}{c|ccccc:ccccc}
\hline & Point 1 & Point 2 & Point 3 & Point 4 & mean & Point 5 & Point 6 & Point 7 & Point 8 & mean \\
\hline $\mathrm{CO}$ & 8.56 & 8.55 & 8.54 & 8.60 & 8.56 & 10.6 & 10.7 & 10.7 & 10.7 & 10.68 \\
$\mathrm{PM}_{10}$ & 0.19 & 0.20 & 0.18 & 0.18 & 0.19 & 0.20 & 0.21 & 0.21 & 0.21 & 0.21 \\
$\mathrm{NO}_{2}$ & 0.20 & 0.23 & 0.21 & 0.20 & 0.21 & 0.25 & 0.25 & 0.25 & 0.25 & 0.25 \\
$\mathrm{THC}^{2}$ & 6.57 & 6.80 & 6.60 & 6.47 & 6.61 & 7.04 & 7.10 & 7.02 & 7.07 & 7.06 \\
\hline
\end{tabular}

To the inside air quality, the mean concentrations of $\mathrm{CO}$ and $\mathrm{NO}_{2}$ inside were less than $10 \mathrm{mg} / \mathrm{m}^{3}$ and $0.24 \mathrm{mg} / \mathrm{m}^{3}$ from China Indoor air quality standard (GB/T 1883-2002), respectively. The inside mean concentration of $\mathrm{PM}_{10}$ exceed the limit of China Indoor air quality standard (GB/T 1883-2002) (i.e. $0.15 \mathrm{mg} / \mathrm{m}^{3}$ ). There is no standard for THC inside and outside currently. As for outdoor air pollutants, the mean concentrations of $\mathrm{CO}, \mathrm{PM}_{10}$ and $\mathrm{NO}_{2}$ outside were more than $10 \mathrm{mg} / \mathrm{m}^{3}, 0.15$ $\mathrm{mg} / \mathrm{m}^{3}$ and $0.20 \mathrm{mg} / \mathrm{m}^{3}$ from China Environment Air Quality Standard (GB3095-2012), respectively.

Influencing Factors of Air Quality at Toll Gates. Fig. 2 showed daily variations of concentrations of air pollutants of two toll stations and the traffic flow. It showed that the traffic flow in TSD increased at 10 a.m. and at 5 p.m., with the concentrations of pollutants began to increase. 
The same trend was also observed in TSZA, where the traffic flow and air pollutants levels were both increased at 9 a.m. and at 5 p.m. Meanwhile, in order to identify the correlation between traffic and air pollution, the results of partial correlation analysis of concentrations of pollutants and traffic flow at toll stations were $\mathrm{P}<0.05$ as shown in Table 2 . It is indicated that the air pollution had the association with the traffic flow.

Table 2. Partial correlation analysis of concentrations of pollutants and traffic flow at toll stations

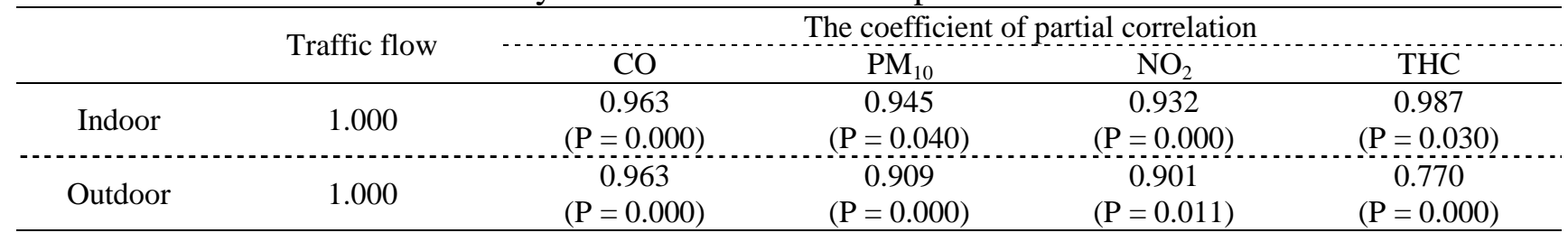

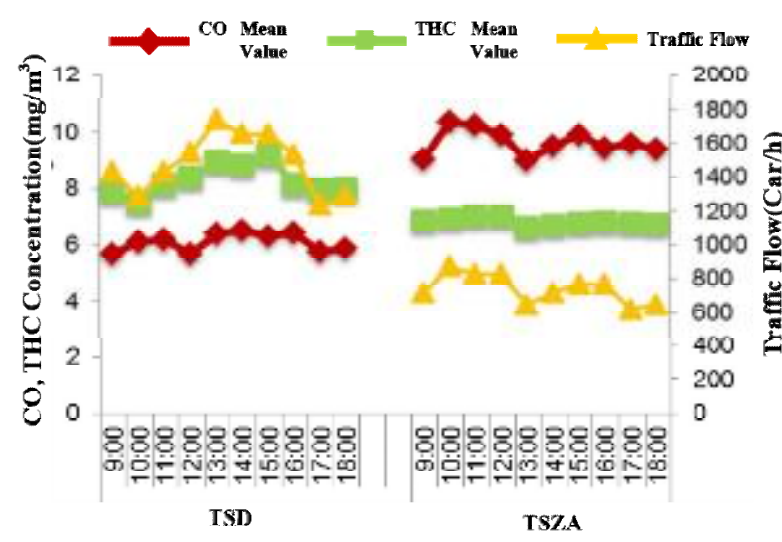

(a)

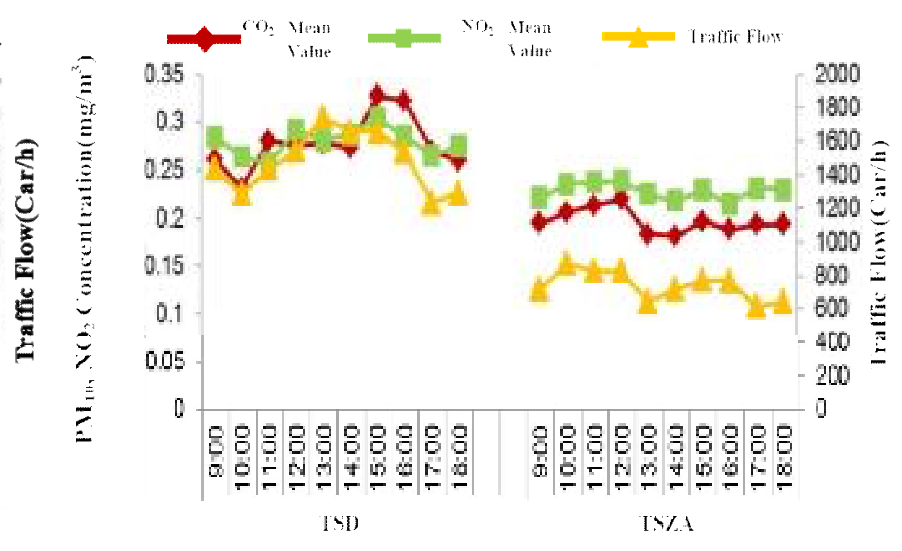

(b)

Fig. 2. The temporal variations of $\mathrm{CO}$ and $\mathrm{THC}(\mathrm{a}), \mathrm{PM}_{10}$ and $\mathrm{NO}_{2}$ (b) in TSD and TSZA.

Table 3 showed the inside and outside air concentrations pollutants and another air concentrations of measuring point located at open space which was far from the toll gate of TSD and TSZA. The concentrations of $\mathrm{PM}_{10}, \mathrm{NO}_{2}$ and THC in TSD were higher than that of TSZA while the concentration of CO in TSZA was higher than that of TSD. The reason of the concentrations of $\mathrm{PM}_{10}, \mathrm{NO}_{2}$ and THC in TSD was higher than that of TSZA was mainly because of traffic flow. The traffic flow in TSD was more than two times than TSZA in a day. But because of the industrial area causing certain degree of industrial soot pollution near TSZA, the concentration of CO in TSZA was higher than that of TSD.

Table 3. The inside and outside air concentrations pollutants of toll stations $\left[\mathrm{mg} / \mathrm{m}^{3}\right]$

\begin{tabular}{ccccc}
\hline Test Site & Pollutants & Indoor mean & Outdoor mean & Far from the toll gates \\
\hline \multirow{6}{*}{ TSD } & $\mathrm{CO}$ & 6.516 & 5.668 & 4.356 \\
& $\mathrm{PM}_{10}$ & 0.300 & 0.256 & 0.187 \\
& $\mathrm{NO}_{2}$ & 0.305 & 0.254 & 0.178 \\
& $\mathrm{THC}$ & 9.275 & 7.354 & 6.432 \\
TSZA & $\mathrm{CO}$ & 8.558 & 10.719 & 6.876 \\
& $\mathrm{PM}_{10}$ & 0.187 & 0.207 & 0.183 \\
& $\mathrm{NO}_{2}$ & 0.208 & 0.248 & 0.168 \\
& $\mathrm{THC}$ & 6.571 & 7.073 & 4.321 \\
\hline
\end{tabular}

In addition, coal-fired nearby also had certain influence to the air pollution in TSZA. And TSD was far from the city, with spacious terrain and without obvious source of pollution. Thus, external pollution source was the main factor to influence air quality in toll station. Furthermore, as shown in Table 2, the inside concentrations of air pollutants in toll gate of TSD was higher than the outside concentrations except $\mathrm{CO}$; and the outside concentrations of air pollutants in TSZA were higher than 
the inside concentrations. Because TSD was far from the city, with spacious terrain and without obvious source of pollution, and was higher than its two sides with good diffusion of outdoor pollutants by north wind, so the concentrations of pollution outside the toll gates were less than that inside the toll gates. On the contrary, the terrain of TSZA was lower than two sides and not conducive to the diffusion of pollutants, so the concentrations of pollution inside the toll gates were less than that outside the toll gates. Therefore, the air diffusion was one of the main factors affecting air pollutants.

\section{Conclusions}

We measured and analyzed statistically $\mathrm{CO}, \mathrm{PM}_{10}, \mathrm{NO}_{2}$ and THC of TSD and TSZA. The conclusion was as follows:

(1) The measurement of $\mathrm{CO}, \mathrm{PM}_{10}, \mathrm{NO}_{2}$ and $\mathrm{THC}$ on highway toll station exceed the Chinese Indoor Air Quality (GB/T 1883-2002) and the Chinese Environment Air Quality (GB 3095-2012).

(2) We explored the characteristics and influencing factors of air pollution in highway toll gates through the binary and partial correlation analysis. These factors which affected indoor and outdoor air quality of toll station contained traffic flow, source of external pollution, including industrial soot pollution and coal-fire nearby, and diffusion.

\section{Acknowledgements}

This research is supported by the China Environmental Protection Project (201509063), the Fundamental Research Funds for the Central Universities of China and the National Nature Science Foundation of China $(51308088,51578103,91743102)$.

\section{Literature References}

[1] P Pant, Shi Z, Pope F D, et al: Characterization of Traffic-Related Particulate Matter Emissions in a Road Tunnel in Birmingham, UK: Trace Metals and Organic Molecular Markers. Aerosol \& Air Quality Research. 17(1), (2017).

[2] X Shen, Yao Z, He K, et al: The Construction and Application of a Multipoint Sampling System for Vehicle Exhaust Plumes. Aerosol \& Air Quality Research. 17(7), (2017).

[3] J W L Goodwin, Salway A G, Murrells T P, et al: UK Emissions of Air Pollutants 1970-99. Effects of Gaseous Air Pollution in Agriculture \& Horticulture. 2(1), (2001). p. 3-26

[4] USEPA: Our Nation's Air, Status and Trends through 2008. (2010).

[5] K Donaldson, Stone V, Seaton A, et al: Ambient particle inhalation and the cardiovascular system: potential mechanisms. Environmental Health Perspectives. 109 Suppl 4(Suppl 4), (2001). p. 523

[6] M W Frampton: Systemic and cardiovascular effects of airway injury and inflammation: ultrafine particle exposure in humans. Environmental Health Perspectives. 109 Suppl 4(Suppl 4), (2001). p. 529

[7] R Meier, Cascio W E, Ghio A J, et al: Associations of short-term particle and noise exposures with markers of cardiovascular and respiratory health among highway maintenance workers. Environmental Health Perspectives. 122(7), (2014). p. 726

[8] L Fu, Hao J, He D, et al: Assessment of Vehicular Pollution in China. Journal of the Air \& Waste Management Association. 51(5), (2001). p. 658

[9] D Shunxi, Jie C, Baichuan L, in: China Environmental Science Vol. 20. 82-85 (2000).

[10]L Y Chan, Lau W L, Zou S C, et al: Exposure level of carbon monoxide and respirable suspended particulate in public transportation modes while commuting in urban area of Guangzhou, China. Atmospheric Environment. 36(38), (2002). p. 5831-5840 